\title{
Erratum to: The Academic Reading Format International Study (ARFIS): Investigating Students Around the World
}

\author{
Diane Mizrachi ${ }^{1(凶)}$, Joumana Boustany ${ }^{2}$, Serap Kurbanoğlu ${ }^{3}$, \\ Güleda Doğan ${ }^{3}$, Tania Todorova ${ }^{4}$, and Polona Vilar ${ }^{5}$ \\ ${ }^{1}$ University of California, Los Angeles, USA \\ mizrachi@library.ucla.edu \\ ${ }^{2}$ Université Paris Descartes, Paris, France \\ jboustany@gmail.com \\ 3 Hacettepe University, Ankara, Turkey \\ \{serap,gduzyol\}@hacettepe.edu.tr \\ ${ }^{4}$ University of Library Studies and Information Technologies, Sofia, Bulgaria \\ t.todorova@unibit.bg \\ 5 University of Ljubliana, Ljubljana, Slovenia \\ polona.vilar@ff.uni-lj.si
}

\section{Erratum to:}

Chapter "The Academic Reading Format International Study (ARFIS): Investigating Students Around the World" in: S. Kurbanoğlu et al. (Eds.): Information Literacy: Key to an Inclusive Society, CCIS,

\section{DOI: 10.1007/978-3-319-52162-6_21}

The original chapter was published in Communications in Computer and Information Science 2016, 676, pp. 215-227.

After publication of the original paper [https://link.springer.com/chapter/10.1007/ 978-3-319-52162-6_21] it came to the authors' attention that the Chinese translation of question 10: I prefer electronic textbooks over print textbooks, was inverted to read I prefer print textbooks over electronic textbooks. Therefore, Figure 3 and the related discussions on pages 220-221 and 227 were incorrect.

The updated original online version for this chapter can be found at DOI: 10.1007/978-3-319-52162-6_21 


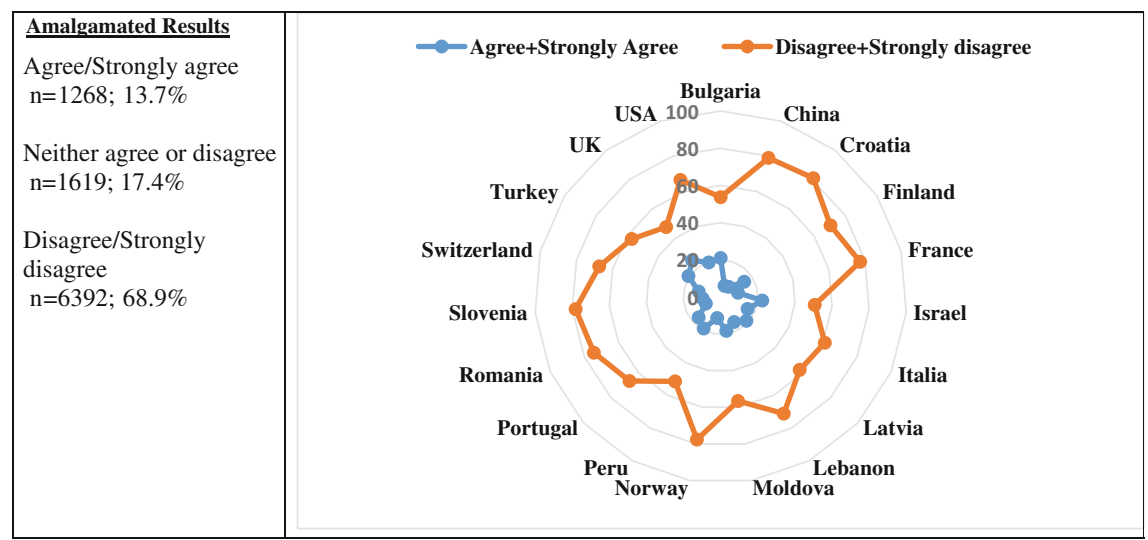

Fig. 3. I prefer electronic textbooks over print textbooks

Electronic textbooks. With more libraries investing in electronic textbooks, it is important to understand our students' attitudes towards using them. Overall, nearly $69 \%$ of the students disagreed with preferring e-textbooks. Figure 3 shows amalgamated results and country percentages for Question 10. 